\title{
Sticky Cost Behavior: Evidence from Egypt
}

Awad Elsayed Awad Ibrahim \& Amr Nazieh Ezat 


\section{Abstract}

Purpose

The purpose of this paper is to provide further empirical evidence on the asymmetric cost behavior, cost stickiness, in an emerging country, Egypt, which lacks academic research on this subject.

Design/methodology/approach

This study uses multiple regression analysis to analyze the behavior of selling, general, and administrative costs (SG\&A) and cost of goods sold (CGS) individually and jointly using total costs (TC) for the period 2004-2011 for Egyptian-listed firms. In addition, the study compares the cost behavior three years prior to and after the application of the corporate governance code in Egypt in 2007.

\section{Findings}

The results indicate that asymmetric cost behavior is common among Egyptian-listed firms as their SG\&A, CGS, and TC were found to be sticky during the study period. The application of the corporate governance code in Egypt was found to affect the nature of SG\&A - the behavior of these costs changed from sticky before the code to anti-sticky after the application of the code. Moreover, the code was found to affect the magnitude of stickiness of both CGS and TC.

Originality/value

Greater awareness about cost behavior is important for emerging markets such as Egypt in order to protect investors' interests and satisfy their information needs. To the best of our knowledge, this study is the first to provide evidence on cost stickiness in Egypt. Moreover, this study provides further evidence on the correlation between corporate governance and asymmetric cost behavior. 


\section{Introduction}

Cost behavior refers to the way costs respond to change in activity and decision. Understanding cost behavior is critical for managers and accountants in order to provide and use information to make effective decisions (Maher et al., 2008). Many stakeholders require timely and relevant information from management accountants for planning, controlling, decision-making, and performance evaluation (Horngren et al., 2012).

From management's perspective, managers need to know how costs behave in order to make informed decisions about products, and to plan and evaluate performance (Lanen, et al., 2011). From investors' perspective, investors depend on the published financial statements prepared by the management that are based on available information regarding the determinants of cost behavior. From financial analysts' perspective, predicting cost behavior is an essential part of earnings prediction (Weiss, 2010).

Traditional cost behavior models distinguish between fixed and variable costs with respect to changes in the level of cost drivers. These models assume that costs behave symmetrically; that is, variables costs may change proportionately with changes in the levels of cost drivers, while fixed costs remain constant regardless of the changes in the levels of the cost drivers.

Recent studies reveal that costs may behave asymmetrically; that is, costs may respond differently to upward or downward changes in activity. Such costs are called sticky coststhe costs increase more for a rise in the activity than they decrease for a fall in the activity by an equivalent amount (Anderson et al., 2003). However, costs that increase less when activity rises than they decrease when activity falls by an equivalent amount are called antisticky (Weiss, 2010; Balakrishnan et al. 2014).

Consequently, the cost estimation methods based on the linear cost assumption may not be applicable to various areas such as cost analysis, planning, control, and pricing. Many traditional techniques such as cost-volume-profit analysis, flexible budgeting, and cost-plus pricing may not provide accurate results. Thus, it is critical to consider the stickiness behavior when classifying costs in order to retain the firm's competitive advantage in the marketplace.

The literature assumes that the stickiness behavior may be due to the deliberate decision taken by the management when activity declines. The deliberate decision and hesitancy of managers to cut slack resources are the key reasons for cost stickiness. Some managers are hesitant to cut slack resources when demand declines, thereby implying that firms bear the costs of unutilized resources that they should not bear. However, when demand flourishes, managers expand resources normally, and thus the related costs increase normally. Therefore, the costs' decrease when demand declines will be lower than the costs' increase when demand increases, resulting in sticky costs. Thus, managers' hesitancy leads to sticky costs, which leads to the question: Why do managers hesitate to cut slack resources when demand declines, while they do not hesitate to hire more resources when demand increases?

Anderson et al. (2003) explain that managers may be hesitant to adjust resources when they feel that the demand decline is temporary. Moreover, managers believe that the adjustment costs of cutting slack resources are higher than the costs of retaining these resources during the short period of demand decline. Therefore, from management's perspective, it is beneficial to deliberate until they are sure that the demand decline is permanent and then adjust the resources downward. If demand recovers, managers do not have to bear the additional adjustment costs of retiring slack resources and then re-hiring them. Therefore, managers prefer to wait until they are sure about the demand change. 
In other words, managers may delay cutting slack resources when demand declines because they make a trade-off between adjustment costs of retiring slack resources and operating with the additional costs of slack resources. If managers believe that the demand decline is temporary, they delay the decision to cut slack resources; however, managers expand the resources normally when demand increases, which leads to sticky cost behavior. This provides evidence regarding managers' behavior when they need to increase or decrease committed resources that results in adjustments to the incurred costs. Thus, managers may be hesitant about cutting resources when sales decline.

The main objective of this paper is to extend prior studies on sticky costs by empirically exploring the stickiness behavior in one of the Middle East countries, Egypt. In this regard, this study examines the cost stickiness for the most actively traded Egyptian-listed companies during 2004-2011. Thereafter, the study seeks to investigate the nature and magnitude of cost stickiness by comparing the cost behavior for two periods - from 20042006, before the application of the Egyptian Corporate Governance (CG) code in 2007, and from 2008-2010, after the application of the code.

The findings indicate that asymmetric cost behavior is prevalent in the Egyptian listed firms as Selling, General, and Administrative costs (SG\&A), Cost of Goods Sold (CGS), and Total Costs (TC) were found to be sticky during the entire study period from 20042011. However, the extent of cost stickiness was $0.18,0.47$, and 0.44 for SG\&A, CGS, and $\mathrm{TC}$, respectively. The findings indicate that asymmetric cost behavior is prevalent even after the application of the CG code in Egypt in 2007. However, the code was found to affect the nature of the SG\&A and the extent of stickiness of CGS and TC. SG\&A changed from sticky prior to the application of the code to anti-sticky after the application of the code. Both CGS and TC remained sticky even after the application of the code, but the extent of cost stickiness was found to be significantly higher after the application of the code.

We examine a sample of firms listed on the Egyptian Stock Exchange (EGX) that may be special to examine. EGX is one of the oldest stock exchanges around the world. EGX was established in 1883 and 1903 in Alexandria and Cairo, respectively. At that time, EGX was considered the fifth largest market in the world (Desoky and Mousa, 2012). Since 1991, Egypt adopted a comprehensive reform program to privatize state owned firms and promote the widespread stock ownership in a movement towards capitalization.

During the study period (2004-2011), EGX and the Egyptian- listed firms have witnessed essential reforms, rapid developments, and higher trading activity that make these firms special to examine. In 2005, the first Egyptian CG Code was issued in light of OECD guidelines. In 2006, the executive rules of CG were issued to be applied on all listed firms in EGX. In 2007, these rules were actually applied on all listed firms as a part of listing requirements. Consequently, the number of listed firms has been declined significantly by more than $100 \%$ from 435 in 2007 to 213 in 2011. According to the 2011 EGX annual report, the trading values have increased by more than 12 times from 42.3 billion in 2004 to 529.6 billion in 2008. However, the trading values have decreased to 448.2, 321, and 148 billion in the years 2009, 2010, and 2011, respectively, due to the 2008 financial crisis and the Egyptian Revolution In January 2011.

On the other hand, the privatization reforms create mixed ownership structures for many Egyptian-listed firms. Ownership structures of some firms may consist of managerial, governmental, institutional, employees and individual investors together.

Consequently, the recent applying of CG in Egypt and the rapid economic developments in EGX, in addition to the mixed ownership structures of the Egyptian-listed firms increase 
the motivation of such study. Investigating cost stickiness in Egypt may be of special interest, since Egypt is an emerging country that lacks such research.

The study of the cost behavior of Egyptian companies is of significance for a number of reasons. First, awareness regarding cost behavior, especially the stickiness behavior, is important in emerging markets like Egypt in order to protect investor's interests and satisfy their information needs; this will enable investors to interpret firms' financial reports and forecast their operating and stock performance accurately. Second, extending prior studies in different contexts helps to document whether similar stickiness behavior is observed for the Egyptian listed companies. Third, the study of the effect of the CG system on stickiness behavior adds to the academic research on the Egyptian CG.

The remainder of this study is organized as follows. Section 2 reviews the literature and formulates the study hypotheses. Section 3 discusses the study methodology. Section 4 presents the data analysis and the study results. Section 5 presents the study's conclusions, implications, limitations, and recommendations for future research.

\section{Literature Review and Hypotheses Formulation}

\section{Literature Review}

One of the first studies that defined and examined cost stickiness was that by Anderson et al. (2003). The study labels costs as sticky when they increase more than they decrease for an equivalent change in activity. Anderson et al. (2003) examine the behavior of SG\&A using data for 7,629 listed firms in the US during the period 1979-1998. They find that SG\&A are sticky and increase by $0.55 \%$ for a $1 \%$ increase in sales, but decrease by $0.35 \%$ for a $1 \%$ decrease in sales. Further, cost stickiness increases during the economic growth periods because managers are optimistic about the demand change. They also find that the larger the assets and labor intensity, the greater is the cost stickiness.

Medeiros and Costa (2004) provide empirical evidence on cost stickiness by analyzing a sample of 198 Brazilian firms for the period 1986-2003. Their results demonstrate that SG\&A increase by $0.59 \%$ for a $1 \%$ sales' increase and decrease by $0.32 \%$ for a $1 \%$ decrease in sales. Further, the cost stickiness increased gradually as the authors aggregated data for two, three, and four years, thus indicating that the extent of cost stickiness is greater over longer periods.

He et al. (2010) examine the cost behavior for a sample of 1,802 Japanese firms for the period 1975-2000 and find evidence on cost stickiness in Japan. Their results indicate that SG\&A are sticky and increase by $0.59 \%$, but decrease by $0.45 \%$ for a corresponding $1 \%$ change in sales. Moreover, the study finds evidence that the economic situation affects the cost behavior-SG\&A were found to be very sticky before the 1990 stock market collapse in Japan, but less sticky in the period after the collapse.

Weiss (2010) examines whether the asymmetric behavior of SG\&A and CGS influences analysts' earnings predictions through investigating a sample of 44,931 industrial firm quarters for 2,520 US- firms during 1986-2005. Findings indicate that firms with stickier cost behavior have less accurate analysts' earnings predictions than firms with less sticky cost behavior. Findings also indicate that investors seem to consider the sticky cost behavior when forming their beliefs about the firms' value, especially with respect to total cost rather than the stickiness of cost components.

Further, Porporato and Werbin (2012) introduce empirical evidence on cost stickiness in the banking sector. They examine three samples of banks from three different countries, Argentina, Brazil, and Canada, for the period 2004-2009. Their results indicate that TC 
increase by $0.60 \%, 0.82 \%$, and $0.94 \%$, and decrease by $0.38 \%, 0.48$, and $0.55 \%$ for $1 \%$ change in sales for the samples of Argentina, Brazil, and Canada, respectively; this indicates different degrees of cost stickiness in the three samples.

Moreover, Dierynck et al. (2012) investigate whether the managerial incentives to meet or beat the zero earnings benchmark influence the labor cost behavior in a total sample of 51, 826 firm-year observations of private Belgian firms during the period 1993-2006. The findings indicate that managers meeting or beating the zero earnings benchmark increase labor costs to a smaller extent when activity increases, but decrease labor costs to a larger extent when activity decreases, which makes labor costs take a more symmetric cost behavior form. Managers of these firms were found to focus on firing employees who are relatively low cost to fire. However, managers of other firms, who do not face significant earnings benchmark pressure, were found to limit the employees' dismissals, which makes labor costs take a more asymmetric cost behavior form.

Kama and Weiss (2013) examine the influence of incentives to meet earnings targets on resources-adjustments and the ensuring cost structures. The study examines a sample of 97,547 firm-year observations for 11,758 different firms during the study period 1979-2006. The findings indicate that when managers face incentives to avoid losses or earnings declines, or to meet financial analysts' earnings forecasts, managers accelerate downward adjustment of slack resources for sales' decline, which mitigates the cost stickiness extent.

Further, Banker and Byzalov (2014) provide a comprehensive framework of asymmetric cost behavior and global evidence on cost stickiness. The study uses data for all countries in the Global Compustat that have at least 2,000 valid observations during the period 1988-2008. The total sample size is 315,967 firm-years across 20 countries. The findings present new comprehensive evidence that asymmetric cost behavior is a pervasive global phenomenon, where operating costs were found to be sticky for 16 countries out of 20. The study also examines some recent claims about the invalidity of some studies' findings and concludes that these claims are groundless.

One recent study, Ciftci et al. (2015), examines whether financial analysts incorporate information on cost stickiness and cost variability in predicting earnings. The results show that analysts "coverage to the average" in recognizing both cost stickiness and cost variability, resulting in substantial and systematic earnings forecast errors. Authors find also that incorporating of available information on cost behavior in earnings' predictions leads to larger errors in unfavorable scenarios than in favorable ones.

Another recent study, Venieris et al. (2015), examines the stickiness of SG\&A and the potential correlation between cost stickiness and intangible investments measured by organizational capital in a sample of 55,769 firm-year observations of US-listed firms during 1979-2009. Findings indicate that SG\&A behavior is asymmetric and that SG\&A in firms with high organizational capital exhibit a sticky cost behavior, while SG\&A in firms with low organizational capital exhibit anti-sticky behavior. Further, findings indicate that firms with high (low) levels of R\&D capital exhibit SG\&A cost stickiness (anti-stickiness).

Few studies have focused on the impact of the stringency of CG systems and legislation on cost stickiness. For example, Calleja et al. (2006) provide a comparative study that examines the stickiness of operating costs in four countries with different CG systems - the UK, the US, France, and Germany. Both UK and US firms are operating under a commonlaw system of $\mathrm{CG}$, while both French and German firms are operating under a code-law regime of CG. The results reveal that the stickiness of operating costs for the French and German firms is greater than that of the UK and US firms. The authors attribute this to the differences in the CG systems. They argue that due to the common-law system of CG, both 
UK and US firms are subject to stricter external scrutiny and have a corporate aim of profit maximization, which results in lesser cost stickiness. However, German and French firms are less subject to the market pressure of corporate control due to the system of CG in these countries.

Another important study is that by Chen et al. (2012) who examine the influence of CG on cost asymmetry. They expect that strong CG will reduce the level of cost stickiness closer to the optimal level of cost response. On examining the SG\&A behavior for a sample of 5,278 US listed firm-year observations for the period 1996-2005, they argue that effective monitoring discourages managers from excessively increasing SG\&A when demand rises and encourages managers to respond normally and cut slack resources when demand declines. The authors find a positive correlation between the agency problem, expressed as empire-building incentives, and the extent of cost asymmetry. Moreover, they demonstrate that this positive correlation is less prevalent in the strong CG sub-sample as compared to the weak CG sub-sample, thereby indicating that strong CG alleviates asymmetric cost behavior.

Further, Banker et al. (2013) examine the impact of strictness of employment protection legislation on the adjustment costs, and thus, the cost behavior. They examine a large sample of 128,333 observations for 15,833 firms located in 19 OECD countries for the period 19902008. They emphasize that the extent of cost stickiness differs according to the level of strictness of the country-level employment protection legislation. In other words, stricter employment protection legislations restrict the ability of firms to cut slack labor resources when demand declines, which in turn increases the cost stickiness. Further, the extent of cost stickiness was found to be greater in countries with stricter labor legislations.

In summation, we find some gaps in the cost stickiness literature. First, we find no study that addresses the cost stickiness behavior in Egypt to date. Second, there is paucity of studies that examine cost stickiness in the context of CG, although many studies argue and find that cost stickiness is a result of managerial interventions. Accordingly, the study key questions are:

Q1: Is the behavior of costs for Egyptian-listed firms asymmetric (either sticky or antisticky)?

Q2: Does the behavior of costs for Egyptian-listed firms remain asymmetric even after the application of the $\mathrm{CG}$ code?

\section{Hypotheses Formulation}

Firstly, we argue that the reasons that lead costs to behave asymmetrically, such as the managers' deliberate decisions toward the resources adjustments when the demand changes (Anderson et al. 2003), could exist in any business environment including the Egyptian one, therefore the study first hypothesis is:

\section{H1: The behavior of costs for Egyptian-listed firms is asymmetric.}

Secondly, the literature argues that managerial behavior is a main reason of cost stickiness (e.g. Anderson et al. 2003), and thus, CG could affect the cost stickiness magnitude through affecting the managers' behavior (e.g. Chen et al. 2012). However, we do not believe that CG could affect cost stickiness for the following reasons. (1) Since the demand changes frequently, it is not easy for managers to respond to each day demand change. The board of 
directors or audit committee members, as CG mechanisms, will not compel managers to respond to each day demand fluctuation. (2) Further, board and audit committee members may not be concerned with decisions made by managers that make costs behave asymmetrically. We argue that those members will not monitor each decision that affects cost behavior. (3) The managers' decisions on adjusting or not adjusting the resources when the demand changes often seem normal, and managers have the ability to persuade board and audit committee members by usefulness of their decisions. (4) Asymmetric response of managers to the equal demand change may be beneficial to the firm performance and value. For example, when the demand declines, managers may decide not to retire highly skilled employees, since they are deemed intellectual capital. This decision may cause costs to behave sticky; however, this decision is in the sake of firm. Therefore, board or committee members cannot blame managers for such decision, even if it makes costs behave sticky. (5) Managers may see that the demand decline is temporary and there is no need to retire the slack resources. Managers think that the costs of operating with slack resources may be lower than costs of retiring these resources and rehiring them again. This decision may cause costs to behave asymmetrically; however, no one can blame managers for this decision, since it seems a rational decision in the sake of the firm. Accordingly, the board and audit committees' members as examples of CG mechanisms may not affect the cost stickiness Therefore, the study second hypothesis is:

\section{H2: The behavior of costs for Egyptian-listed firms remains asymmetric even after the application of the corporate governance code.}

\section{Methodology}

\subsection{Sample}

The study examines the stickiness behavior of the most actively traded Egyptian listed companies for the period 2004-2011. The Egyptian Stock Exchange classifies listed companies into 11 sectors. The financial and banks sectors were excluded from the sample due to differences in the standardized financial reports. The remaining 9 sectors are represented by at least one actively traded company in the sample

Table (1) summarizes the initial and final sizes of the study's main samples and subsamples. To investigate the impact of the application of the CG code in Egypt in 2007, the study considers the three-year period prior to the application of the code (2004-2006) and that after the application (2008-2010). The study makes a comparison between the two periods to document whether the application of the CG code in Egypt has an impact on the cost stickiness behavior of Egyptian listed companies.

We follow some selection criteria followed by related prior literature. First, we exclude observations with missing data on costs or revenues. Second, we discard observations if costs exceed revenues for the current year. Third, following Cannon (2014), we discard extreme observations where the value of the standardized residuals of any observation is more than the absolute value of three.

\section{Insert Table 1 about here}

\subsection{Variables Measurement and Study Model}

The literature shows that many proxies are used to examine asymmetric cost behavior. Anderson et al. (2003), Medeiros and Costa (2004), He et al. (2010), Balakrishnan et al. 
(2014), and Chen et al. (2012) use SG\&A as proxy. Subramaniam and Weidenmier (2003) and Nicola and Paolo (2013), among others, use CGS as proxy. Calleja et al. (2006) and Banker et al. (2013), among others, use operating costs as proxy. Some studies such as Subramaniam and Weidenmier (2003) and Porporato and Werbin (2012) use TC as proxy. However, this study uses three proxies for cost, SG\&A, CGS, and TC, due to study limitations.

Thus, this study replicates the model by Anderson et al. (2003) that uses SG\&A as proxy for cost and sales revenue as proxy for activity. Further, this study replicates two models by Subramaniam and Weidenmier (2003) that use CGS and TC as proxies for costs and sales revenues as proxy for activity. Thus, the three models used in this study are:

\author{
Model (1): \\ $\log \left\{\right.$ SGA $\left._{\mathrm{it}} / \mathrm{SGA}_{\mathrm{it}-1}\right\}=\beta 0+\beta 1 \log \left\{\mathrm{Sales}_{\mathrm{i}, t} / \mathrm{Sales}_{\mathrm{i}, \mathrm{t}-1}\right\}+\beta 2 \operatorname{DecDummyLog}\left(\mathrm{SaleS}_{\mathrm{i}, t} / \mathrm{Sales}_{\mathrm{i}, \mathrm{t}-1)}\right)+\Sigma$ \\ Model (2):

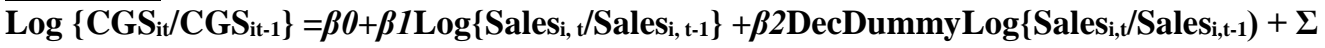 \\ Model (3): \\ $\log \left\{\right.$ TC $\left._{i t} / \mathrm{TC}_{i t-1}\right\}=\beta 0+\beta 1 \log \left\{\right.$ Salesi, $\left._{\mathrm{t}} / \mathrm{Sales}_{\mathrm{i}, \mathrm{t}-1}\right\}+\beta 2 \mathrm{DecDummyLog}\left\{\mathrm{Sales}_{\mathrm{i}, t} / \mathrm{Sales}_{\mathrm{i}, \mathrm{t}-1}\right)+\Sigma$
}

\title{
Where:
}

$S G A$ it refers to the SG\&A of firm $i$ during the year $t$; SGAit-1 refers to the SG\&A of firm $i$ during the year $t-1$; CGSit stands for CGS of firm $i$ during the year $t$; CGSit-1 stands for CGS of firm $i$ during the year $t-1$; TCit stands for TC in the current year and is the sum of SG\&A and CGS, as measured by Subramaniam and Weidenmier (2003); TC $_{i t-1}$ stands for TC of the prior year; Salesit refers to sales of firm $i$ during the year $t$; Salesit-1 refers to sales of firm $i$ in the prior year; DecDummy is a dummy variable that equals one if the current year net sales are less than the prior year net sales, and equals zero otherwise.

\section{Data Analysis}

This study uses quantitative research methods based on secondary data. The primary variables used in our analysis are SG\&A, CGS, TC, and net sales. Further, data for all these variables are obtained from either annual reports or the websites of Egyptian-listed firms for the period 2004-2011.

\subsection{Descriptive Statistics}

Table (2) presents descriptive information about annual revenues, SG\&A, CGS, and TC for the complete 8-year samples. The mean value of SG\&A as a percentage of sales revenues is $11 \%$ (median $=6 \%$, standard deviation $=13 \%$ ), which is lower than the ratios of $26 \%$ and 24\% reported by Anderson et al. (2003) and Chen et al. (2012), respectively. The mean value of CGS as a percentage of sales revenues is $61 \%$ (median $=67 \%$, standard deviation $=26 \%$ ), which is comparable with the mean value of $63.77 \%$ reported by Subramaniam and Weidenmier (2003). The mean value of TC as a percentage of sales revenues is $67.57 \%$ (median $=74.05 \%$, standard deviation $=24.92 \%)$ as compared to $88.2 \%$ reported by Subramaniam and Weidenmier (2003). Porporato and Werbin (2012) reported mean values of $79.01 \%, 69.05 \%$, and $87.42 \%$, for Argentina, Brazil, and Canada, respectively.

\section{Insert Table 2 about here}

\subsection{Multivariate Analysis Results}




\subsubsection{Existence of Cost Stickiness}

For multivariate analysis, we estimate the three models by running Ordinary Least Squares (OLS). Table (3) shows the regression results of SG\&A, CGS and TC models. The analysis finds that the three models are statistically significant at $\mathrm{p}<0.001$; Adj. $\mathrm{R}^{2}=0.24$ and F-ratio $=81.06$ for the SG\&A model, adj. $R^{2}=0.67$ and F-ratio $=425.48$ for the CGS model, and adj. $\mathrm{R}^{2}=0.55$ and F-ratio $=234.35$ for the TC model.

\section{Insert Table 3 about here}

Regarding the SG\&A model, Table (3) shows that the estimated value of $B_{1}$ is $0.35(t=$ 11.53), which indicates that SG\&A increase by $0.35 \%$ for a $1 \%$ increase in sales revenues. The estimated value of $B_{2}$ is $-0.18(t=-3.05)$, which supports the hypothesis of sticky costs. The combined value of $B 1$ and $B 2$ is 0.17 , which indicates that SG\&A decreased by about $0.17 \%$ for a $1 \%$ decrease in sales revenues. Both $B_{1}$ and $B_{2}$ are significant at $1 \%$ (p-value = 0.001). Our findings support $H_{l}$, which indicates that Egyptian listed companies exhibit stickiness behavior. These results are consistent with many prior studies such as Anderson et al. (2003), Mederios and Costa (2004), Balakrishnan et al. (2014), Chen et al. (2012), and Dierynck et al. (2012).

Regarding the CGS model, Table (3) demonstrates that the estimated value of $B_{1}$ is 0.87 $(t=26.51)$, which indicates that CGS increases by $0.87 \%$ for a $1 \%$ increase in sales revenues. Further, the estimated value of $B_{2}$ is $-0.47(t=-7.21)$, which again supports the hypothesis of sticky costs. The combined value of $B_{1}$ and $B_{2}$ is 0.40 , which indicates that CGS decreases by $0.40 \%$ for a $1 \%$ decrease in sales revenues. Both $B_{1}$ and $B_{2}$ are significant at $1 \%$ (p-value $=0.001$ ), which provides additional evidence on cost stickiness behavior. These results are consistent with Subramaniam and Weidenmier (2003) who find evidence on stickiness of CGS for large samples of firms from different industries. Subramaniam and Weidenmier (2003) find that CGS is sticky when revenues change by more than $10 \%$.

We provide some explanations for stickiness of CGS. First, the raw materials cost is a main component of CGS. Suppliers regularly induce managers to order large quantities at lower costs; this discount reduces the costs of raw materials per unit than was predicted by the cost/volume linear regression model. Further, the purchase of large quantities increases the inventory intensity. Prior studies argue and find that inventory intensity increases the costs stickiness. For example, Subramniam \& Weidenmier $(2003,17)$ state, "Inventory intensity increases the stickiness of SG\&A and CGS costs in manufacturing, merchandising, and service firms." Second, labor cost is also a main component of CGS. When the demand declines, managers may decide to retain the highly skilled employees, since they are deemed intellectual capital, managers may not be able to rehire them again when the demand recovers. Further, learning curves explain that labor costs are more likely to reduce gradually, since learning improves efficiency and productivity, and thus reduces the unit cost. Accordingly, CGS could be a sticky according to the behavior of its cost components.

Regarding the TC model, Table (3) shows that both coefficients $B 1$ and $B 2$ are statistically significant at $1 \% ; B_{1}$ is positive, and $B_{2}$ is negative, which is consistent with the cost stickiness hypothesis. Moreover, the estimated value of $B_{1}$ is 0.83 , which indicates that when demand increases by $1 \%$, TC increases by $0.83 \%$. Further, the sum of both $B_{1}$ and $B_{2}$ values is 0.39 , indicating that when demand decreases by $1 \%$, TC decreases by $0.39 \%$, which provides evidence on cost stickiness of TC. Moreover, the extent of TC stickiness in the current study is $0.44 \%$, but that found by Subramaniam and Weidenmier (2003) is $0.08 \%$ 
and by Porporato and Werbin (2012) are $0.22 \%, 0.82 \%$, and $0.94 \%$ for the study's three samples.

To summarize, this study provides empirical evidences on the stickiness behavior of costs in the Egyptian business environment, where SG\&A is found to be sticky to the extent of $0.18 \%$, CGS is found to be sticky to the extent of $0.47 \%$, and TC is found to be sticky to the extent of $0.44 \%$. These empirical results support the study's first hypothesis.

\subsubsection{Cost Behavior before and after the Egyptian CG Code}

To test hypothesis $\mathrm{H}_{2}$, the study runs the three models again for comparing between two periods. The first period covers three years prior to the application of the CG code (2004 2006) and the second covers three years after the application of the code (2008-2010).

\section{SG\&A Model}

Table (4) presents the results obtained by using SG\&A as a proxy for costs, before and after the application of the code. First, the results for the period before the application of the CG code are as follows. The estimated value of $B_{l}$ is $0.41(t=7.87)$, which indicates that SG\&A increased by $0.41 \%$ for a $1 \%$ increase in sales revenues. The estimated value of $B_{2}$ is $-0.37(t=-3.08)$, which supports the hypothesis of sticky costs before the application of the code. The combined value of $B_{1}$ and $B_{2}\left(B_{1}+B_{2}\right)$ is 0.04 , which indicates that SG\&A decrease by about $0.04 \%$ for a $1 \%$ decrease in sales revenues. Both $B_{1}$ and $B_{2}$ are significant at $1 \%$ (p-value $=0.001)$.

The results for the period after the application of the CG code are as follows. The estimated value of $B_{1}$ is $0.10(t=2.23)$, which indicates that SG\&A increase by $0.10 \%$ for a $1 \%$ increase in sales revenues. The estimated value of $B_{2}$ is $0.18(t=2.36)$, which indicates that costs are anti-sticky after the application of the code. The combined value of $B_{1}$ and $B_{2}$ $\left(B_{1}+B_{2}\right)$ is 0.28 , which indicates that SG\&A decrease by about $0.28 \%$ for a $1 \%$ decrease in sales revenues. Both $B_{1}$ and $B_{2}$ are significant at $5 \%$ (p-value $=0.05$ ).

\section{Insert Table 4 about here}

These findings provide additional support to the hypothesis that SG\&A stickiness behavior exists even after the application of the CG code in Egypt. However, the behavior of the costs has changed from sticky before the code to anti-sticky after the code. After the code, the SG\&A were found to decrease more when sales revenues decrease than increase when sales revenues increase by an equivalent amount. Moreover, this behavior indicates that applying the $\mathrm{CG}$ code mitigates the stickiness behavior by transforming the costs' behavior from sticky into anti-sticky.

One explanation for this lies in the rigid regulations of the $\mathrm{CG}$ code. Another explanation may be the pessimistic view of the Egyptian companies during the period after the application of the code that witnessed the 2008 financial crisis. This is indicated by the decrease in sales revenues for most Egyptian listed companies in the period after the application of the code. Banker et al. $(2013,2014)$ highlight that managers may be more pessimistic when they expect sales revenues to decline, leading to anti-stickiness behavior.

Our results are consistent with those of Calleja et al. (2006) who find that cost stickiness in the UK and US firms is less than the cost stickiness in the French and German firms. They attribute this difference to the different CG systems applied in these countries. Further, 
our results are consistent with those of Chen et al. (2012) who find that strong CG alleviates the extent of cost stickiness. Moreover, Chen et al. (2012) argue that strong CG may reduce the level of cost stickiness closer to the optimal level of cost response, since strong monitoring systems lead managers to respond normally to demand changes; consequently, costs behave normally and do not exhibit a sticky behavior.

To conclude, in general, our findings support the stickiness behavior of SG\&A before and after the application of the code; however, the nature of cost stickiness has changed from sticky to anti-sticky, which may be attributable to the application of the CG code. Thus, our findings support $H_{2}$ that states that stickiness behavior persists even after the application of the CG code.

\section{CGS Model}

The results are different when CGS is used as a proxy for costs. In Table (5), for the period before the application of the CG code, the estimated value of $B_{1}$ is $0.86(t=28.56)$, which indicates that CGS increase by $0.86 \%$ for a $1 \%$ increase in sales revenues. The estimated value of $B_{2}$ is $-0.18(t=-2.19)$, which supports the cost stickiness hypothesis before the application of the code. The combined value of $B_{1}$ and $B_{2}$ is 0.68 , which indicates that CGS decreases by about $0.68 \%$ for a $1 \%$ decrease in sales revenues. The coefficient $B_{1}$ is significant at $1 \%$, and $B_{2}$ is significant at $5 \%$. To conclude, the results confirm the stickiness of CGS during the period before the application of the code.

\section{Insert Table 5 about here}

For the period after the application of the $\mathrm{CG}$ code, the estimated value of $B_{1}$ is $0.60(t$ $=8.48$ ), which indicates that CGS increases by $0.60 \%$ for a $1 \%$ increase in sales revenues. The estimated value of $B_{2}$ is $-0.29(t=-2.79)$, which supports the hypothesis of sticky costs after the application of the code. The combined value of $B_{1}$ and $B_{2}\left(B_{1}+B_{2}\right)$ is 0.31 , which indicates that CGS decreases by about $0.31 \%$ for a $1 \%$ decrease in sales revenues. Both $B_{1}$ and $B_{2}$ are significant at $1 \%(\mathrm{p}$-value $=0.001)$. These findings support $\mathrm{H}_{2}$, which again provides strong evidence on the existence of stickiness behavior after the application of the CG code. However, the extent of cost stickiness has increased from 0.18 before the code to 0.29 after the application of the code.

One explanation for this is the managers' deliberate intervention in the resources adjustment process when demand changes, which is a form of real earnings management. Cohen et al. (2008) conclude that effective monitoring mechanisms through the implementation of a strong CG system reduce opportunities for accounting earnings management and direct managers towards real earnings management tools. Cohen and Zarowin (2010) and Gunny (2010) indicate that real earnings management and accrualsbased earnings management are negatively correlated. To summarize, we find that after the application of the 2007 CG code in Egypt, cost stickiness increased and this may have driven managers to engage in real earnings management. However, providing empirical evidences on managers' engaging in real earnings management is not a concern of this study.

\section{TC Model}

The results obtained by using TC as proxy for costs are similar to those obtained by using CGS. Table (6) shows that for the period before the application of the CG code, both coefficients $B_{1}$ and $B_{2}$ are statistically significant at $1 \%$ and $5 \%$, respectively. The estimated value of $B_{1}$ is positive (0.80) and of $B_{2}$ is negative (-0.17), which supports the cost stickiness 
hypothesis before the application of the code. The table shows that for the period after the application of the code, both $B_{1}$ and $B_{2}$ are statistically significant at $1 \%$. Further, the estimated value of $B_{1}$ is positive $(0.87)$ and of $B_{2}$ is negative $(-0.62)$, which also supports the cost stickiness hypothesis after the application of the $\mathrm{CG}$ code.

\section{Insert Table 6 about here}

The TC analysis results support the second hypothesis that cost stickiness behavior persists even after the application of the CG code. Moreover, the results indicate that the extent of cost stickiness increased from 0.17 before the code to 0.62 after the code, which implies that the code has affected only the extent of cost stickiness. Further, these results are similar to those of CGS - the extent of stickiness of both CGS and TC was found to increase after the application of the code, however the extent of TC stickiness (0.62) was greater than that of CGS (0.29).

Since the increase in stickiness of TC after the application of the code is similar to the results for CGS, we propose the same explanations for the TC behavior before and after the code. We propose that managers' intervention in the resources adjustment process is a kind of real earnings management that is expected to increase after the application of the CG system; Cohen et al. (2008) find that managers engage in real earnings management instead of accounting earnings management after the application of CG. We argue that applying the CG code in Egypt may direct managers towards real earnings management and increase their interference in the resources adjustment process. Thus, we find that TC are stickier after the application of the CG code.

Finally, while the nature of the SG\&A was found to change from sticky to anti-sticky after the application of the code, the nature of both CGS and TC was found to remain sticky. However, the extent of CGS stickiness increased from 0.18 before the code to 0.29 after the code, while the extent of TC stickiness increased from 0.17 before the code to 0.62 after the code. These results provide empirical evidence that support this study's hypotheses. First, the costs for the Egyptian-listed firms were found to respond asymmetrically to demand changes - SG\&A, CGS, and TC exhibited a sticky behavior during the entire study period. Second, cost stickiness persisted even after the application of the CG code, which is consistent with the study second hypothesis. SG\&A were found to be sticky before the code and anti-sticky behavior after the code, while both CGS and TC were found to be sticky before and after the code. However, the extent of both CGS and TC stickiness increased after the application of the code.

\subsection{Additional Analysis}

Balakrishnan et al. (2014) suggest that focus on firms within a narrowly defined industry is one of the three ways to potentially reduce the influence of cost structure and economic climate in the study of sticky costs as such firms presumably have similar cost structures and scale economies. Consequently, we conduct additional cross-sectional analysis to provide further evidence on the stickiness behavior for Egyptian listed companies. We run the three models for 9 sectors out of 11 sectors classified by the Egyptian stock market in 2011, after excluding the banking and financial sectors.

\section{SG\&A Model}

Table (7) illustrates the results of the SG\&A model. Except for the industrial, and tourism sectors, the SG\&A for all the Egyptian listed sectors was found to behave 
asymmetrically. The coefficient $B 1$ for the industrial sector was insignificant, and the coefficient $B 2$ for the tourism sector was insignificant, which rejects the cost stickiness hypothesis. In addition, the results indicate that all the other sectors exhibit anti-sticky cost behavior, except the real estate sector that exhibits sticky cost behavior. Thus, the anti-sticky behavior seems to be dominant. However, this behavior is not supported by many prior studies. These results are consistent with Balakrishnan et al. (2014) who find evidence on anti-sticky cost behavior for 3 of 25 industries. Finally, the cross-sectional analysis provides additional evidence on the asymmetric behavior of SG\&A for the Egyptian listed firms.

\section{Insert Table 7 about here}

\section{CGS Model}

Table (8) shows the results of the cross-sectional analysis of CGS. The table illustrates that the results for three sectors, industrial, textiles, and real estate, are insignificant; the remaining six sectors exhibit asymmetric cost behavior. Moreover, the food and mining sectors exhibit anti-sticky behavior, while the remaining four sectors exhibit sticky behavior. These results are consistent with the agency theory that supports the deliberate decision of the managers of Egyptian companies to fulfill self-interest through the sticky cost behavior. Further, Subramaniam and Weidenmier (2003) examine stickiness for some sectors separately and find that CGS is sticky for manufacturing, financial, and service firms. To conclude, the CGS results provide evidence on the asymmetric cost behavior for six of the nine examined sectors.

\section{Insert Table 8 about here}

\section{TC Model}

Table (9) exhibits the results of the cross-sectional analysis of TC. Only the results of the industrial and textiles sectors are not statistically significant; the remaining seven sectors show significant results. Further, the table shows that the TC of five sectors (construction, chemicals, real estate, telecommunication, and tourism) exhibit sticky behavior - all their $B_{1}$ coefficients are positive and statistically significant, and all their $B_{2}$ coefficients are negative and statistically significant, which is consistent with the cost stickiness hypothesis. In contrast, the $\mathrm{TC}$ of both food and mining sectors were found to be anti-sticky. The results of TC indicate that asymmetric cost behavior is prevalent in the Egyptian listed firms, which is consistent with this study's first hypothesis.

\section{Insert Table 9 about here}

To conclude, the cross-sectional analysis provides additional evidence on the asymmetric cost behavior for the Egyptian listed firms for the three examined costs (SG\&A, CGS, and TC). However, this asymmetric behavior differs across sectors and costs.

\section{Results and Implications}

The results show that cost stickiness is prevalent in the data of the Egyptian-listed firms. Further, the cross-sectional analysis shows that stickiness is prevalent in majority of sectors. We find that SG\&A, CGS and TC behave asymmetrically during the entire study period 2004-2011, consistent with prior studies, such as Anderson et al. (2003), Medeiros and 
Costa (2004), He et al. (2010), Weiss (2010), Porporato and Werbin (2012), and Banker and Byzalov (2014).

Further, the results show that the Egyptian governance code may affect the cost stickiness nature and extent, but may not mitigate its magnitude. The results show that SG\&A behavior changed from sticky behavior before the CG code into anti-sticky after applying the CG code in 2007. However, both CGS and TC remained sticky after the application of the CG code, but their stickiness magnitude increased. However, these results disagree with those of Calleja et al. (2006) and Chen et al. (2012) that CG systems could alleviate the cost stickiness magnitude.

Moreover, the study results confirm the arguments of the asymmetric cost behavior theory as presented by Banker and Byzalov (2014), those of the deliberate decisions' hypothesis as presented by Anderson et al. (2003), and those of resources-adjustment costs theory as explained by Anderson et al. (2003) and Baumgarten (2012).

The implications of cost behavior are of primary interest not only to management accountants (Weiss, 2010), but also to investors, analysts, governance regulators, researchers, and managers. The study results leave important implications for all these parties. First, for investors and market analysts, they should take into consideration that cost behavior is not always linear as assumed by the traditional cost model. Therefore, they should undertake earnings prediction cautiously. Second, management accountants should take into consideration the sticky cost behavior when undertaking the cost estimation and allocation and when making the budgets, since these techniques depend on the traditional cost model that assumes that costs behave linearly with cost drivers. Third, the governance authorities should recognize that governance could affect the nature and extent of cost stickiness; therefore, they should provide more effective governance rules that mitigate the cost stickiness. Fourth, for researchers, this study provides empirical evidence on cost stickiness from an emerging market and evaluates the effect of governance code on cost behavior. Finally, for managers, they should adjust the resources normally as a response to the sales change, as possible as they can, to avoid a higher degree of cost stickiness, otherwise, they should provide acceptable justifications for their response to the sales changes, and should tell management accountants of their resources adjustments decisions that are likely to make costs behave sticky.

\section{Conclusions, Implications, Limitations, and Directions for Future Research}

This study seeks to extend the results of the extant research by examining whether (1) costs behave asymmetrically in the Egyptian business environment and (2) cost behavior differs before and after the application of the CG code in Egypt in 2007. Moreover, the study explores the stickiness behavior at many levels. First, the study examines if the stickiness behavior of costs is dependent on revenue changes for the most actively traded Egyptian listed companies during 2004-2011. This analysis involves using SG\&A and CGS as proxies for costs, individually and jointly. The results indicate that all the examined costs, SG\&A, CGS, and TC, exhibit sticky behavior; that is; they increase more than they decrease when demand changes by an equivalent amount.

Second, the study investigates and compares the stickiness behavior for two periods: before the application of the CG code (2004-2006) and after the application of the CG code (2008-2010). The reason for this comparison is to demonstrate if there are any changes in 
the stickiness behavior during these two periods. The results of this analysis indicate that nature of SG\&A changes from sticky before the code to anti-sticky after the code. In addition, the CGS and TC exhibit sticky behavior both before and after the application of the CG code; the magnitude of both CGS and TC stickiness increased significantly after the application of the code.

Third, the study examines the stickiness behavior for different sectors in Egypt. Examining each industry separately provides greater insights into the cost behavior and different impacts on the magnitude of stickiness (Subramaniam and Weidenmier, 2003). The cross-sectional analysis supports the stickiness behavior of SG\&A and CGS (individually and jointly) for the Egyptian listed firms. However, stickiness is a feature of certain industries and this asymmetric behavior differs across sectors and costs. The study illustrates that stickiness is not prevalent in all sectors.

The study's results provide some implications for both researchers and practitioners in Egypt. First, for researchers, this study extends the previous studies by examining the stickiness behavior in a developing country, Egypt. In addition, this study is one of the studies that combines the perspectives of management and financial accounting that encourages researchers to exploit this multi-disciplinary approach in examining various research topics. One such research topic is exploring the relationship between the stickiness behavior for Egyptian listed companies and earnings management. Second, for practitioners, it is more beneficial to consider sticky costs when estimating the average amount of change in costs due to a unit change in the activity driver in order to avoid either underestimation or overestimation of the responsiveness of costs to increases or decreases in activity. This may aid the managements of Egyptian companies in making precise decisions based on accurate cost analyses.

An important limitation of this study is the use of a comparison approach to examine the impact of CG on cost behavior where the findings may be due to circumstances other than the application of the CG code. Moreover, no CG variable is examined in this study. Further, it would be more beneficial if incorporated the governance compliance levels in the study models; however, we did not find any data on governance compliance levels in the Egyptian emerging market during the study period. Another limitation is the small sample size used as compared to the large samples of the other related studies.

Future research may examine the determinants of sticky costs in addition to the CG variables that are expect to influence the cost behavior in the Egyptian context. Further, it may be useful to study the consequences of sticky cost behavior by investigating whether the stickiness behavior has an impact on the firm value of the listed Egyptian companies. Further, in the cost accounting area, studying the effect of sticky costs on standard costs tools may add more value to the existing research.

\section{References}

1. Anderson, M. C., Banker, R. D. and Janakiraman, S. N. (2003), "Are selling, general, and administrative costs sticky?” Journal of Accounting Research, Vol. 41 No. 1, pp. 47-63.

2. Awad, A. E. (2012), "Investigating impact of historical costing on real earnings management: an

3. Balakrishnan, R. E., Labro, E. and Soderstrom, N. S. (2014), "Cost structure and sticky costs", Journal of Management Accounting Research, Vol. 26, No. 2, pp. 91-116.

4. Banker, R. D. and Byzalov, D. (2014), "Asymmetric cost behavior", Management Accounting Research, Vol. 26, No. 2, pp. 43-79. 
5. Banker, R. D., Byzalov, D. and Chen, L.T. (2013), "Employment-protection legislation, adjustment cost and cross-country differences in cost behavior", Journal of Accounting \& Economics, Vol. 55, No. 1, pp. 111-127.

6. Baumgarten, D. (2012). "The cost stickiness phenomenon: causes, characteristics, and implications for fundamental analysis and financial analysts' forecasts”. Gabler Verlag, Springer Fachmedien Wiesdbadn.

7. Belsley, D.A., Kuh, E. and Welsch, R. E. (1980), Regression Diagnostics: Identifying Influential Data and Sources of Collinearity, Wiley, New York, NY.

8. Calleja, K., Steliaros, M. and Thomas, D. C. (2006), "A note on cost stickiness: some international comparisons", Management Accounting Research, Vol. 17, No. 2, pp. 127-140.

9. Cannon, J. N. (2014), "Determinants of sticky costs: an analysis of cost behavior using United States air transportation industry data", The Accounting Review, Vol. 89, No. 5, pp. 1645-1672.

10. Chen, C. X., Lu. H. and Sougiannis. T. (2012), "The agency problem, corporate governance, and the asymmetric behavior of selling, general, and administrative costs", Contemporary Accounting Research, Vol. 29 No. 1, pp. 252-282.

11. Ciftci, M., Mashruwala, R., and Weiss, D. (2015), 'Implications of cost behavior for analysts' earnings forecasts", Journal of Management Accounting Research, In-Press.

12. Cohen, D.A., Dey, A. and Lys, T.Z. (2008), "Real and accrual-based earnings management in the pre- and post-Sarbanes Oxley periods”, The Accounting Review, Vol. 83, No. 3, pp. 757-787.

13. Cohen, D.A and Zarowin, P. (2010), "Accrual-based and real earnings management activities around seasoned equity offerings", Journal of Accounting \& Economics, Vol. 50, No. 1, pp. 2-19.

14. Desoky, A. M. and Mousa, G. A. (2012), "Do board ownership and characteristics affect on firm performance? Evidence from Egypt", Global Advanced Research Journal of Economics, Accounting and Finance, Vol. 1, issue. 2, pp. 015-032.

15. Dierynck, B., Landsman, W. R. and Renders, A. (2012), "Do managerial incentives drive cost behavior? Evidence about the role of the zero earnings benchmark for labor cost behavior in Belgian private firms", The Accounting Review, Vol. 87, issue. 4, pp. 1219-1246.

16. Gunny, K. A. (2010), "The relation between earnings management using real activities manipulation and future performance: evidences from meeting earnings benchmarks", Contemporary Accounting Research, Vol. 27, issue. 3, pp. 855-888.

17. He, D. S., Jenny, T. and Shimizu, T. (2010), "Sticky selling, general, and administrative cost behavior and its changes in Japan", Global Journal of Business Research, Vol. 4 No. 4, pp. 1-10.

18. Herrmann, D., Inoue, T. and Thomas, W.B. (2001), "The sale of assets to manage earnings in Japan”, Journal of Accounting Research, Vol. 41 No. 1, pp. 89-108.

19. Horngren, C. T., Datar, S. M. and Rajan, M., (2012), Cost Accounting: A Managerial Emphasis, $14^{\text {th }}$ ed., Prentice Hall, United States.

20. Kama, I. and Weiss, D. (2013), "Do earnings targets and managerial incentives affect sticky costs?" Journal of Accounting Research, Vol. 51, No. 1, pp. 201-224.

21. Kennedy, P. (1992), A Guide to Econometrics, MA: The MIT Press, Cambridge.

22. Lanen, W. N., Shannon, W. S. and Maher, M. W. (2011), Fundamentals of Cost Accounting, $3^{\text {rd }}$ ed., McGraw-Hill, New York, NY.

23. Malcolm, R. E. (1991), "Overhead control implications of activity costing", Accounting Horizons, Vol .5, pp. 69-78.

24. Maher, M.W., Stickney, C. P. and Weil, R. L. (2008), Managerial Accounting: An Introduction to Concepts, Methods and Uses, $10^{\text {th }} \mathrm{ed}$, Centage Learning, United Kingdom.

25. Medeiros, O. R. and Souza Costa, P. (2004), "Cost stickiness in Brazilian firms", available at: http://papers.ssrn.com/sol3/papers.cfm?abstract_id=632365 (accessed 10 May 2014). 
26. Noreen, E. and Soderstrom, N. (1997), "The accuracy of proportional cost models: evidence from hospital services departments", Review of Accounting Studies, Vol. 2, pp. 89-114.

27. Nicola, D. V. and Paolo, P. (2013), "Sticky cost behavior: Evidence from small and medium sized companies", available at: http://ssrn.com/abstract=2226399 (accessed 20 April 2014).

28. Porporato, M. and Werbin, E. (2012), "Evidence of sticky costs in banks of Argentina, Brazil, and Canada”, International Journal of Financial Services Management, Vol. 5 No. 4, pp. 303-320.

29. Subramaniam, C. and Weidenmier, M. L. (2003), "Additional evidence on the sticky behavior of costs", working paper, Texas Christian University, Texas.

30. Venieris, G., Naoum, V. C. and Vlismas, O. (2015), "Organizational capital and sticky behaviour of selling, general and administrative expenses", Management Accounting Research, Vol. 26, March Issue, pp. 54-82.

31. Weiss, D. (2010), "Cost behavior and analysts' earnings forecasts", The Accounting Review, Vol. 85, No. 4, pp. 1441-1474. 